\title{
The Influence of Ultrasonic Impact Peening on the Mechanical Properties of Similar Friction Stir Welded Joints of AA 7075-T73
}

\author{
Abdul Ameer H. Jebur ${ }^{\text {a* }}$, Samir A. Amin ${ }^{\text {b }}$, Ibtihal A. Mahmood \\ anstitute of Tech. , Middle Technical University, Baghdad, Iraq. \\ ${ }^{a, b}$ Mech. Eng. Dept, University of Technology, Baghdad, Iraq. \\ *Corresponding author Email: amiralrubaeee@gmail.com
}

\section{H I G H L I G H T S}

- Welded joints of $\mathrm{Al}$ 7075-T73 were achieved by FSW.

- The joints were treated by one pass and two passes of ultrasonic peening.

- Tensile Strength of joints was enhanced by $14 \%$ by one pass and $11 \%$ by two passes.

\section{A R T I C L E I N F O}

Handling editor: Muhsin J. Jweeg

Keywords:

Aluminum alloy

Friction stir welding

Ultrasonic peening

Mechanical properties

\section{A B S T R A C T}

The purpose of this study is to study the ultrasonic peening influence upon the mechanical properties of the welded joints of $3 \mathrm{~mm}$ AA 7075-T73. Friction stir welding (FSW) was carried out by using milling machine and cylindrical tool with tapered pin. The used welding parameters were $710 \mathrm{rpm}, 35 \mathrm{~mm} / \mathrm{min}$ for rotational and travel speed, respectively. Tensile tests results showed that the welding efficiency was about $60 \%$ for welded samples , and this value increased by using one and two lines ultrasonic peening treatment to $74 \%$, and $71 \%$, respectively, this improvement is due to generating compressive stresses along the surface of welded joints. The microhardness of the welded samples showed that there were fluctuations across the welded centerline and minimum hardness occur in the heat affected zone (HAZ).

\section{Introduction}

The friction stir welding (FSW) has been widely utilized to weld aluminum alloys, such as $2 \mathrm{xxx}$, 7xxx series which are difficult to be welded with TIG technique $[1,2]$. The $7 x x x$ series is especially applied to aircraft fittings, gears and shafts, fuse part, missile parts, regulating valve parts, worm gears, keys, aircraft, aerospace and defense applications [3], and applications of AA 7075-T73 have been specially aged to make the material resistant to stress-corrosion [4]. Important properties, like formability, corrosion resistance, and high strength to weight ratio of Al alloys have created them used widely in the automotive and aerospace industries. The new application of Al sheet in the automobiles body panels is a remarkable technique, which can considerably decrease the vehicle's weight. The producers of automobile are moving from the steels toward the alloys of $\mathrm{Al}$ for producing lighter, harmless, and highly effective automobiles [5, 6]. FSW is carried out with a nonconsumable rotating tool that possesses a shoulder and a pin at the shoulder end to plunge into the base metal and progresses in the direction of welding, when the shoulder touches a top surface; then the pin shifts the solid state of weld about it [7]. Friction stir welded joints contain (3) different zones: Stir Zone SZ or Nugget Zone NZ, Thermo-Mechanically Affected Zone TMAZ and Heat-Affected Zone HAZ. The stir region undergoes the severe plastic deformation and relatively a high heat input resulting in the fine and equiaxed grains formation, the thermo-mechanically affected region lies near to the stir region and experiences comparatively less plastic deformation, and the heat-affected region doesn't undergo any plastic deformation and endures merely the thermal influences [8]. The defects, such as tunnel, groove and cavity can be formed due to improper of welding speed and welding pressure. Friction stir welding is one of the most energy efficient processes. The major challenge for the aluminum producers, is to achieve a high quality and defect free welded joints, especially $2 \mathrm{xxx}$ and $7 \mathrm{xxx}$ series. The defects, such as tunnels, kissing bonds and flash are familiar in the FSW joints. The kissing bond reduces the life of fatigue, whereas it doesn't influence considerably the tensile strength [9, 10]. It is important to carry out the FSW of the Al alloys in a wider variety of rotational speeds and welding speeds, since the mechanical properties of joints depend on many conditions, such as travel speed, rotational speed, tool geometry and thickness of material $[11,12]$. Ultrasonic peening treatment UPT is a 
recent technique that improves the chemical and mechanical properties of the welded joints, and also lengthens the fatigue life of these joints loading conditions [13,14]. Many researchers were investigated the effect of the ultrasonic impact treatment UIT on the microstructure, hardness and residual stress distribution of welded joints [15]. These studies have been focused on the enhancement the mechanical properties of welded steel plates that welded by conventional gas metal arc welding by using ultrasonic impact peening, while this study is the first try to modify the friction stir welded joints by using this technique.

The present work aims to show the influence of ultrasonic peening technique that generate compressive stresses in order to improve the mechanical properties of similar friction stir welded joints for aluminum alloy 7075-T73.

\section{Experimental work}

\subsection{Material selection}

Aluminum alloy plates of AA7075-T73 with a thickness of $3 \mathrm{~mm}$ were selected in order to be joined via FSW. By using punch cutter, these plates were cut into dimensions of $150 \times 75 \times 3 \mathrm{~mm}$. The chemical analysis of this alloy was obtained via utilizing the spectrometer analysis device available in the General Company for Examination and Rehabilitation Engineering, as depicted in Table 1. The mechanical properties of this alloy are summarized in Table 2. These tables also list the standard values for the conformity and comparison purposes.

Table 1: The actual and standard chemical composition of AA 7075-T73

\begin{tabular}{cccccccccccc}
\hline Component & Fe & Si & Cu & Mn & Mg & Cr & Ni & Zn & TI & Pb & Al \\
\hline Standard & 0.5 & 0.4 & $1.2-$ & 0.3 & $2.1-$ & $0.18-$ & 0.05 & $5.1-$ & 0.2 & 0.15 & Bal. \\
ASM $\boldsymbol{w t \%}$ & Max & Max & 2 & Max & 2.9 & 0.28 & Max & 5.6 & Max & Max & \\
Actual $w \boldsymbol{w} \%$ & 0.228 & 0.099 & 1.47 & 0.07 & 2.13 & 0.21 & 0.003 & 5.61 & 0.02 & 0.13 & Bal. \\
\hline
\end{tabular}

Table 2: The mechanical properties of 7075-T73

\begin{tabular}{ccccc}
\hline Property & $\begin{array}{c}\text { Yield } \\
\text { Strength(MPa) }\end{array}$ & $\begin{array}{c}\text { Ultimate Strength } \\
\text { (MPa) }\end{array}$ & $\begin{array}{c}\text { Elongation, } \\
\text { \% }\end{array}$ & $\begin{array}{c}\text { Modulus of Elasticity } \\
\text { (GPa) }\end{array}$ \\
\hline Standard & 386 & 462 & 16 & 72 \\
Actual & 392 & 489 & 14.5 & 72.5 \\
\hline
\end{tabular}

\subsection{Welding process}

Milling machine type (GmbH Knuth Werkzeug machine, Germany) and fixture system were used to obtain similar butt welded joints of aluminum alloys AA7075-T73 by friction stir welding, as shown in Figure 1. In this study, FSW was conducted by using tool made from tool steel type BS-82 with an average hardness value of 62 HRC. The diameter of the tool shoulder is $15 \mathrm{~mm}$, whereas the base and top pin diameters are $5 \mathrm{~mm}$ and $3 \mathrm{~mm}$, respectively with a height of $2.85 \mathrm{~mm}$, which is somewhat lower than the thickness of plate $3 \mathrm{~mm}$, as shown in Figure 2.

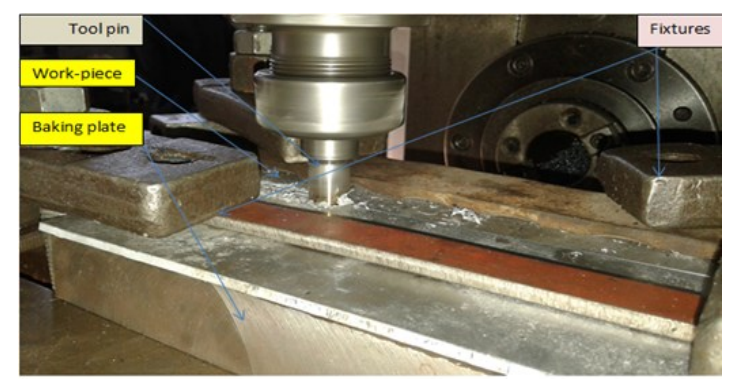

Figure 1: Milling Machine and Fixture System

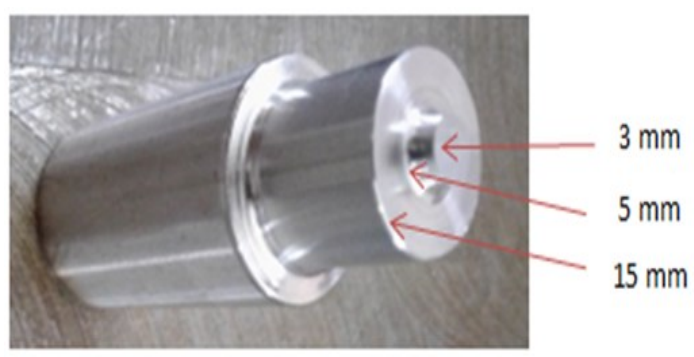

Figure 2: Cylindrical tapered Pin Tool

\subsection{Parameters of welding}

FSW processes operations were performed at various parameters of welding, including a travel speed of 35,45 and 60 $\mathrm{mm} / \mathrm{min}$, a rotational speed of 500, 710 and $900 \mathrm{rpm}$, tilt angle $2^{\circ}$ and dwelling time $30 \mathrm{sec}$.

\subsection{Ultrasonic impact peening}

To improve the mechanical properties of welded joints, an ultrasonic peening device type HC-S-1, as shown in Figure 3 was used to introduce the energy of ultrasound into the material through the surface impulse contact, and such energy is introduced into the metal in order to convert the harmonic oscillation of an acoustically tuned body into mechanical impulses 
[16]. One-line peening 1UP or one pass and two lines peening 2UP or two passes post welded peened treatment were achieved on welded specimens in order to remove tensile stresses and obtain compressive stresses, as shown in Figure 4 and Table 3.

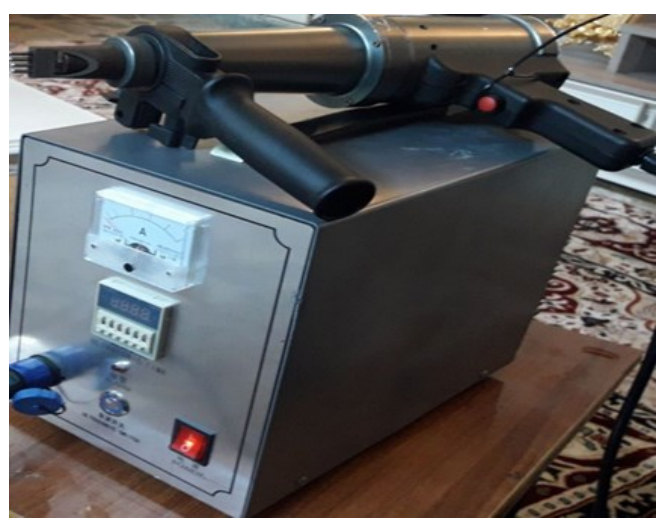

Figure 3: Ultrasonic peening device type HC-S-1

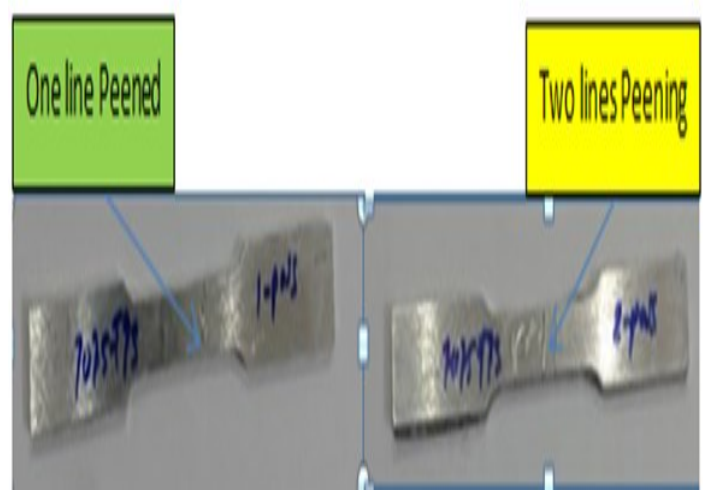

Figure 4: Ultrasonic peened specimen

\section{Tests and Inspections}

\subsection{Radiography, X- Ray inspection}

To ensure if that the welded joints are sounds without defects, such as cracks or gaps or not, the radial unit which operate at $130 \mathrm{kV}, 3 \mathrm{~mA}$ for 2 min was used to identify these defects. Radiographic apparatus was utilized in this investigation, which is available in the General Company for Engineering Inspection and Qualification.

\subsection{Microstructure inspection}

The microstructure of FSW joints were assessed by Optical Microscope and this operation was accomplished by using water and emery paper of SiC in several grits of 400, 600, 800, 1000 and 1200. The polishing was performed on the samples by using $0.5 \mu \mathrm{m}$ diamond paste and special cloth for polishing and lubricant. The etching solution Killer's reagent (Composition: $95 \mathrm{ml} \mathrm{H} 2 \mathrm{O}, 2.5 \mathrm{ml} \mathrm{HNO} 3,1.5 \mathrm{ml} \mathrm{HCl}$, and $1.0 \mathrm{ml} \mathrm{HF}$ ) was utilized [17].

\subsection{Mechanical tests under ultrasonic peening}

The ultrasonic peening process is one of the popular and modern techniques used to improve the mechanical properties of the welded joints. Numbers of ultrasonic peening treatments were carried out on the welded specimens, such as one-line peening 1UP (one pass) and two lines peening 2UP (two passes).

\subsection{Tensile test}

Tensile tests were performed to each friction stir welded sample in order to determine the tensile properties of the friction stir welded joints with and without ultrasonic peening treatment (one line1 UP or two lines 2UP) at the room temperature by utilizing a universal testing machine (model WDW-200E). Tensile specimens were cut and machined by using CNC milling machine type Rapimill-700 in a direction perpendicular to the welding direction according to the ASTM standard E8M-09 for the subsize specimens, as revealed in Figure 5 [18].

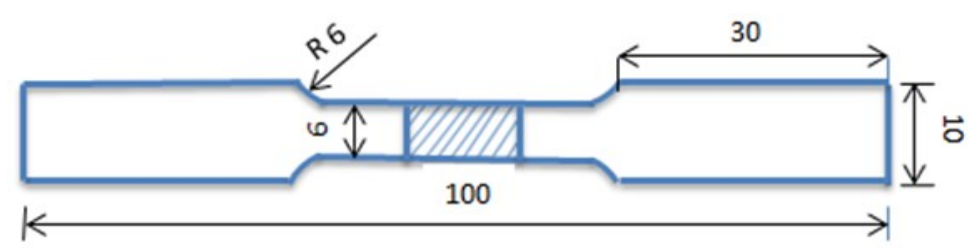

Figure 5: Sample for tensile test (all dimensions are in $\mathrm{mm}$ ) [18]

\subsection{Microhardness test}

The Vickers hardness was conducted on welded samples (with and without ultrasonic peening treatment) which were cut from across section of FSW joints via utilizing digital microhardness tester, type Laryee, Model HVS-1000 and according to the ASTM standard E92-82 [19]. A $200 \mathrm{~g}$ load for 15 secs was applied along the cross section of welded joints. 


\section{Results and Discussion}

\subsection{X- Ray inspection}

The X-ray radiographic inspection was conducted on all the FSW welded joints, it was found that the images did not contain any defects, such as revealed voids, cracks or penetration according to ASTM standard E155 [20]. as evinced in Figure 6.

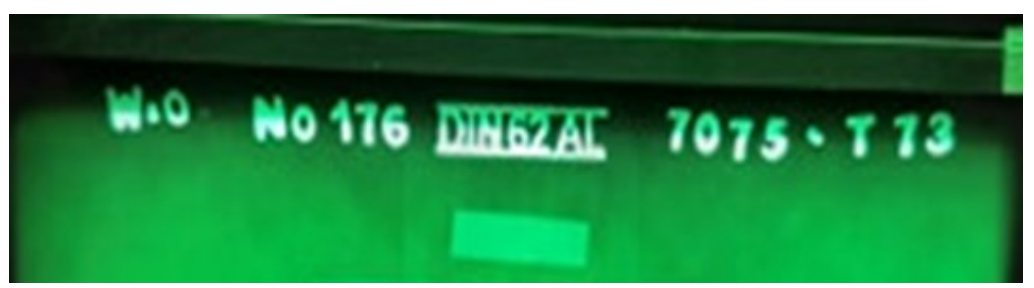

Figure 6: X-Ray radiographs image

\subsection{Microstructure result}

The test revealed that are three different microstructural zones, including SZ, TMAZ, and HAZ in the friction stir welded joints after one line peened of AA 7075-T73. It was observed from Figure 7 that there were elongated grains with certain precipitates dispersed in the aluminum alloy mold having a cross section alike the friction stir welded joints. There's no variation in the structure of grain, and there's no plastic deformation in the HAZ, while there was a plastic deformation in the microstructure of SZ and TMAZ due to the largest heat that resulted too fine grains.

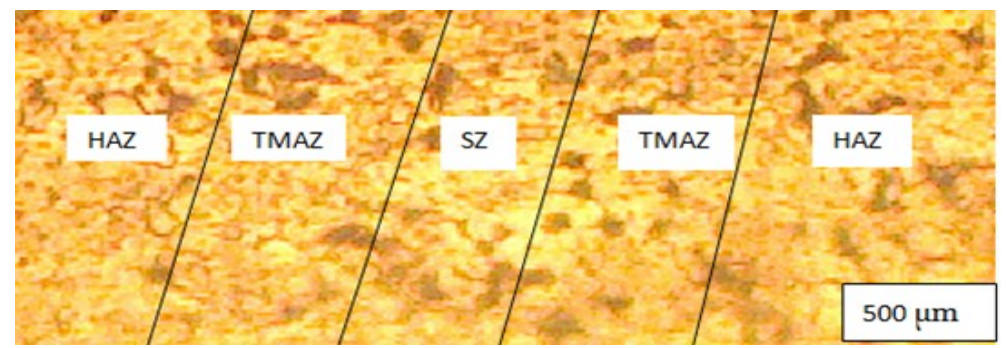

Figure 7: Micrograph of FSW One line peened zones of 7075-T73

\subsection{Tensile results}

The tensile tests result of similar welded joints were obtained with the best parameters of welding, including a rotational speed of $710 \mathrm{rpm}$, a travel speed of $35 \mathrm{~mm} / \mathrm{min}$, and a cylindrical tool with tapered pin geometry, as evinced in Figures 8-9. The tensile strength of the welded joints was lower than of the base alloy due to inhomogeneity in chemical composition and microstructure in different welding zones as reported by Singh et al. [21]. The ultrasonic peening treatment was conducted on the welded joints at the best parameters of welding, as manifested in Table 4 and Figure 10. From this table, it is seen that the tensile strength of welded samples with one-line peening 1UP is higher than of two lines peening 2UP. The tensile strength average with three readings measured for four conditions (Base, Welded, one line peened and Two lines peened), as summarized in the Table 3, which includes the results before and after the ultrasonic peening treatment. The comparison reveals that the ultimate tensile strength of specimen under ultrasonic peening UP more than the welded untreated joints. The ultimate strength values were $74.6 \%, 71.6 \%$ and $60.3 \%$ under 1UP, 2 UP and welded conditions, respectively. The situation of specimen before and after tensile tests for all cases is shown in Figure 11.

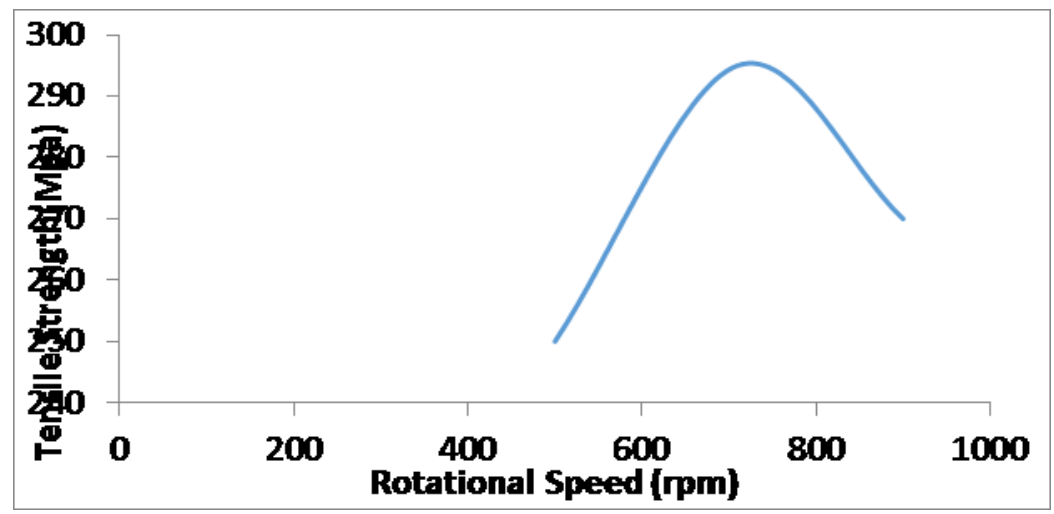

Figure 8: Effect of Rotational Speed on the Tensile Strength 


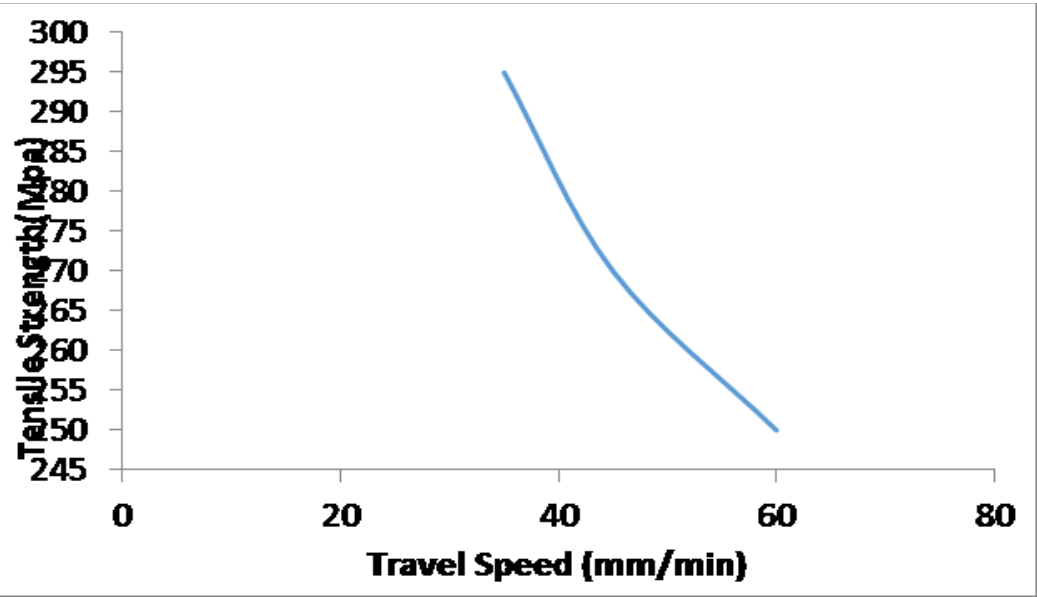

Figure 9: Effect of Travel Speed on the Tensile Strength

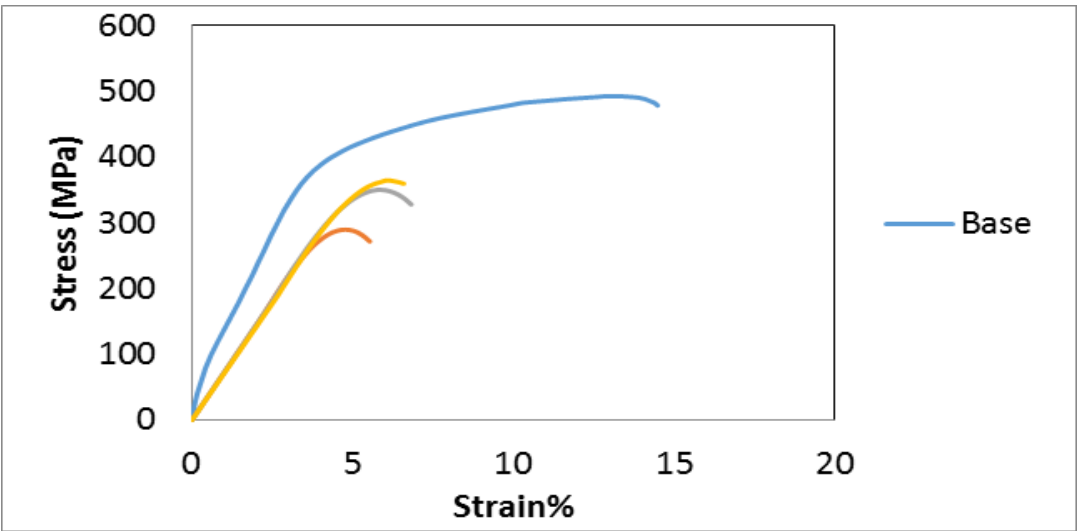

Figure 10: Stress-Strain diagrams of 7075-T73 for different conditions

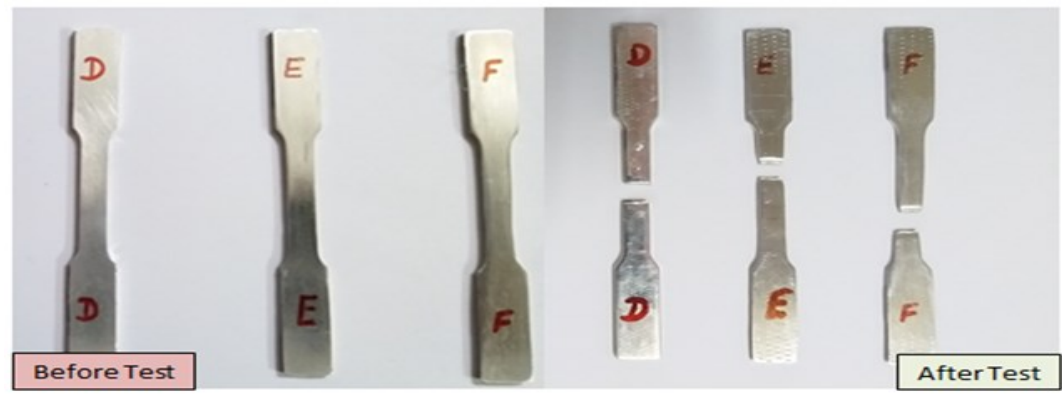

Figure 11: Tensile specimens before and after test

Table 3: Different Conditions of Ultrasonic Impact Peening

\begin{tabular}{cc}
\hline Symbol & Ultrasonic Impact Peening Conditions \\
\hline D & Welded without Peening \\
E & Welded with One line Peening \\
F & Welded with Two lines Peening
\end{tabular}

Table 4: Tensile test results

\begin{tabular}{ccccc}
\hline Specimen & $\begin{array}{c}\text { Yield } \\
\text { strength } \\
\text { (MPa) }\end{array}$ & $\begin{array}{c}\text { Tensile strength } \\
\text { (MPa) }\end{array}$ & joint efficiency \% & $\begin{array}{c}\text { Elongation } \\
\%\end{array}$ \\
\hline $\mathrm{D}$ & 225 & 295 & 60 & 5 \\
$\mathrm{E}$ & 300 & 365 & 74 & 6.3 \\
$\mathrm{~F}$ & 285 & 350 & 71 & 6.1 \\
\hline
\end{tabular}




\subsection{Microhardenss results}

The microhardness results of welded joints before and after ultrasonic peening treatment are shown in Figure12. For welded joints before ultrasonic peened treatment, the hardness increased in stir zone SZ to 234.7HV compared with TMAZ and HAZ, which reached to maximum values of $158.1 \mathrm{HV}$ and $196.6 \mathrm{HV}$, respectively. The hardness for welded joints with one-line peening 1UP in stir zone was 382.5 HV compared with TMAZ and HAZ, which reached to values of 260.3 and 182.1 $\mathrm{HV}$. The hardness for welded joints with two lines peening 2UP in stir zone of 264.6 compared with TMAZ and HAZ, which reached to values of $246.2 \mathrm{HV}$ and $223.3 \mathrm{HV}$, while the hardness value is $155 \mathrm{HV}$ for the base metal BM. The difference in the microhardness values among the HAZ, TMAZ, and NZ is owing to the refinement of the grain and the equiaxed dynamic recrystallization in nugget zone NZ. The softened HAZ is due to the coarsening and dissolution of the strengthening precipitates or the second phase particles throughout the FSW process, and this result was confirmed by many researchers such as Barcellona et al. [22]. Most of the tensile specimens were failed in the HAZ because of the microhardness values, in which the lowest value, while the local material softening took place in the weld area resulted via the thermal action of the process of welding.

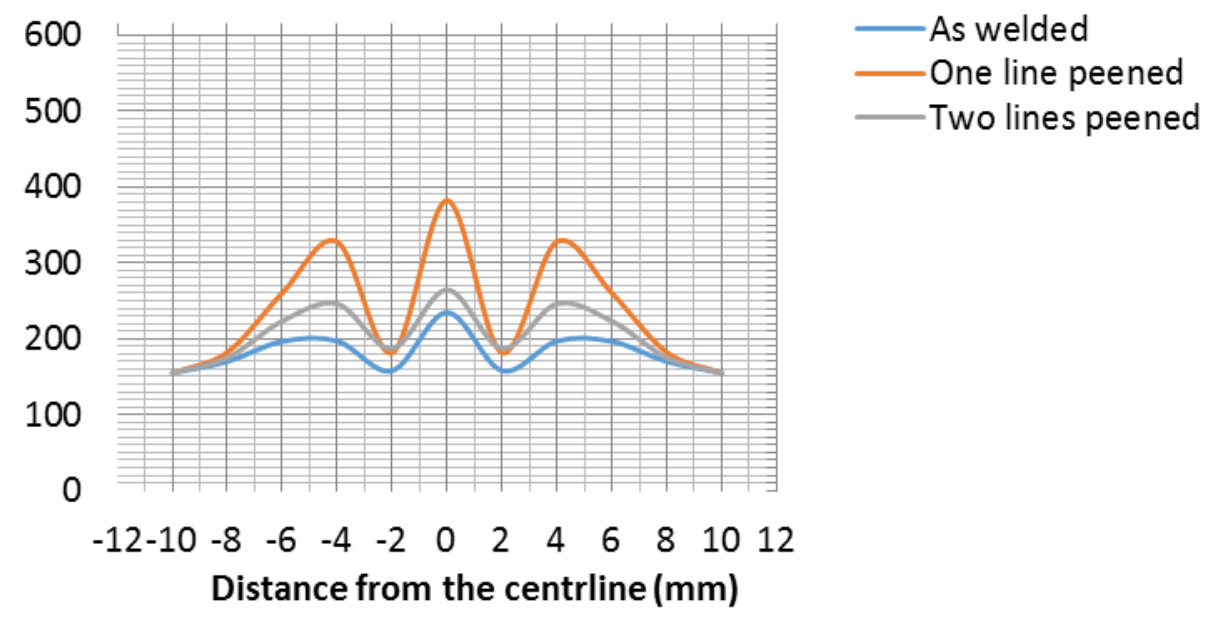

Figure 12: Microhardenss distribution of 7075-T73 for different conditions

\section{Conclusions}

1) The similar welded joints of aluminum alloys Al 7075-T73 were successfully performed via the FSW process.

2) The ultrasonic peened treatment was performed on the welded joints with one and two lines peening, and more suitable improvement for mechanical properties was with one line peening.

3) The microhardness in the stir zone SZ was greater than that of the thermo-mechanically affected zone TMAZ) and the heat-affected zone HAZ due to the grain refinement.

4) The enhancement of the tensile strength with one-line peening 1UP was 14\% compared with the as welded samples.

5) The enhancement of the tensile strength with two lines peening $2 \mathrm{UP}$ was only $11 \%$ compared with the as welded samples.

\section{Author contribution}

All authors contributed equally to this work.

\section{Funding}

This research received no specific grant from any funding agency in the public, commercial, or not-for-profit sectors.

\section{Data availability statement}

The data that support the findings of this study are available on request from the corresponding author.

\section{Conflicts of interest}

The authors declare that there is no conflict of interest.

\section{References}

[1] I. Shigematsu, Y. J.Kwon, K Suzuki, T. Imai and N. Saito, "Joining of 5083 and 6061 aluminum alloys by friction stir welding," Journal of Materials Science Letters 22, pp. 353-356, 2003. 
[2] M. Guerra, C. Schmidt, L.C. McClure, L.E. Murr and A. C Nunes, "Flow patterns during friction stir welding," Materials Characterization 49, pp. 95-101, 2003.

[3] Alloy 7075 plate and sheet, 2007.

[4] C. Blawert, N. Hort and K.U. Kainer, “Automotive Applications of Magnesium and its Alloys," Trans. Indian Inst. Met. Vol. 57, No. 4, pp. 397-408, August 2004.

[5] R. Roth, J. Clark and A. Kelkar, “Automobile bodies: Can aluminum be an economical alternative to steel?” JOM, 53, pp. 28-32, 2001

[6] R.S. Mishra and Z.Y. Ma, "Friction stir welding and processing," Materials Science and Engineering: R. Vol.50, No. 1-2 pp. 1-78, August 2005.

[7] J. G. Perrett, J. Martin, P. L. Threadgill and M.M.Z. Ahmed, "Recent Developments in Friction Stir Welding of Thick Section Aluminum Alloys," The 6th World Congress, Aluminum Two Thousand, Florence, Italy, 13-17 March 2007.

[8] P.L.Threadgill, "Friction stir welds in aluminum alloys-preliminary microstructural assessment," TWI Bull., 28, pp. 30-33, 1997.

[9] M. Kadlec, R. Růžek and L. Nováková., "Mechanical behavior of AA 7475 friction stir welds with the kissing bond defect," Int. J. Fatigue, Vol. 74, pp. 7-19, 2015.

[10] T. Le Jolu, T. F. Morgeneyer, A Denquin, M. Sennour, A Laurent, J. Besson and A. F. Gourgues-Lorenzon, "Microstructural characterization of internal welding Defects and their effect on the tensile behavior of FSW joints of AA2198 Al-Cu-Li alloy,” Metal \& Mater. Trans. A., 45, 12, pp. 5531-44, 2014.

[11] R. Mishra, M.W. Mahoney, Y. Sato, Y. Hovanski and R.Verma,"Friction Stir Welding and Processing VII,” John Wiley and Sons, 29 January 2013.

[12] R. S. Mishra, Z.Y. Ma and I. Charit., "Friction stir processing: a novel technique for fabrication of surface composite," Materials Science and Engineering A, Vol. 341, No.1-2, 20 January 2010.

[13] M. Massoud and H. Ding, "A review of ultrasonic peening treatment," Materials \& Design, Vol. 87, pp.1072-1086, December 2015.

[14] R. Zhang, X. Li, Y. Liu, C. He and Q. Wang, "Effect of Ultrasonic Peening Treatment on VHCF Behavior of Friction Stir Welded Joints in Aluminum Alloys," IOP Conf. Series: Materials Science and Engineering 611,012011, Wuhan, china, 19-21 July 2019.

[15] L. Chuan, C. Dongjun, R. Michael, N. Minh and Z. Jiasheng, "Effects of ultrasonic impact treatment on weld microstructure, hardness, and residual stress," Materials Science and Technology, Vol. 33, No. 14, pp. 1601-1609, 2017.

[16] Hangzhou Create Ultrasonic Technology Co. Ltd, "Ultrasonic Generator, Ultrasonic pre stressing force impact treatment system," Operation instruction.WW. hzcreate. eng. Alibaba.Com, 2013.

[17] ASM Handbook, "Metallography and Microstructures," American Society for Metals, Vol. 9, 2004.

[18] Standard Test Methods for Tension Testing of Metallic Materials, E8M-09, ASTM, 2010.

[19] Standard Test Method for Vickers Hardness of Metallic Materials, E92-82, ASTM, 2003.

[20] Standard Reference Radiographs for Inspection of Aluminum and Magnesium Castings, E155, ASTM, 2014.

[21] R.K.R. Singh, C. Sharma, D.K. Dwivedi , N.K. Mehta, and P. Kumar , "The microstructure and mechanical properties of friction stir welded $\mathrm{Al}-\mathrm{Zn}-\mathrm{Mg}$ alloy in as welded and heat treated conditions," Journal Materials and Design, Vol. 32, No.2, pp. 682-687, 2011.

[22] A. Barcellona, G. Buffa., L. Fratini, and D. Palmeri, "Microstructural phenomena occurring in friction stir welding of aluminum alloys," Journal of Material Processing Technology, 177, pp. 340-343, 2006. 